Dieses Volum wird nun in 100 Theile getheilt, so dass $10 \mathrm{Grm}$. Stärke, die ganz wasserfrei wäre, es gerade erfüllen und jeder Grad weniger 1 Proc. Wassergehalt ausdrückt. (Compt. rend. T. 39. - Chem.-pharm. Centrbl. 1855. No. 2.)

$B$.

\title{
Ueber die Verbindungen des Glycerins mit den Säuren.
}

Berthelot hat neuerdings folgende Körper dargestellt:

1) Triolein $\mathrm{C}^{114} \mathrm{H}^{104} \mathrm{O}^{12}=3 \mathrm{C}^{36} \mathrm{H}^{34} \mathrm{O}^{4}+\mathrm{C}^{6} \mathrm{H}^{8} \mathrm{O}^{6}$ - 6 HO. Es ist flüssig und neutral. Mit Bleioxyd bei $100^{\circ}$ behandelt, theilt es sich langsam und schwierig in Oleinsäure und Glycerin. Fs ist identisch mit dem natiirlichen Olein.

2) Trivalerin $\mathrm{C}^{36} \mathrm{H}^{32} \mathrm{O}^{12}=3 \mathrm{C}^{10} \mathrm{H}^{10} \mathrm{O}^{4}+\mathrm{C}^{6} \mathrm{H}^{8} \mathrm{O}^{6}$ - 6 HO. Eine neutrale ölige Flüssigkeit von einem unangenehmen Geruch, unlöslich in Wasser, löslich in Alkohol und Aether. Spaltet sich in Glycerin und Baldriansäure.

3) Tributyrin $\mathrm{C}^{30} \mathrm{H}^{26} \mathrm{O}^{12}=3 \mathrm{C}^{8} \mathrm{H}^{8} \mathrm{O}^{4}+\mathrm{C}^{6} \mathrm{H}^{8} \mathrm{O}^{6}$ - 6 HO. Eine neutrale, ölige, wohlriechende Flüssigkeit, von einem spec. Gew. $=1,056$. Spaltet sich in Glycerin und Buttersäure.

4) Tribenzoicin $\mathrm{C}^{48} \mathrm{H}^{20} \mathrm{O}^{12}=3 \mathrm{C}^{14} \mathrm{H}^{6} \mathrm{O}^{4}+\mathrm{C}^{6} \mathrm{H}^{8} \mathrm{O}^{6}$ - $6 \mathrm{HO}$. Es reagirt neutral. Im gereinigten Zustande krystallisirt es in schönen weissen Nadeln.

5) Triacetin $\mathrm{C}^{18} \mathrm{H}^{14} \mathrm{O}^{12}=3 \mathrm{C}^{4} \mathrm{H}^{4} \mathrm{O}^{4}+\mathrm{C}^{6} \mathrm{H}^{8} \mathrm{O}^{6}$ - 6 HО. Hine neutrale, wohlriechende Flüssigkeit, von einem spec. Gew. $=1,174$, unlöslich in Wasser, aber leicht löslich in verdünntem Alkohol. Es enthält $C^{49,9}$, $\mathrm{H}^{6,8}$. Die Formel verlangt $\mathrm{C}^{49,6}, \mathrm{H}^{6,4}$. Es spaltet sich beim Verseifen in Essigsäure und Glycerin. Es hat also ergeben :

$$
\begin{aligned}
& \text { Essigsäure...... . 80,6 } \\
& \text { Glycerin. . . . . . . 43,1 } \\
& 123,7 \text {. }
\end{aligned}
$$

Die Formel verlangt:

$$
\begin{array}{rr}
\text { Essigsäure } \ldots \ldots \ldots & 82,6 \\
\text { Glycerin. . . . . } & 42,2 \\
& \\
& 124,8 .
\end{array}
$$

Die beim Studium obiger Körper gefundenen analytischen Resultate, und vorzugsweise die Analyse und Verseifung des Triacetins, haben Berthelot veranlasst, die allgemein für das natürliche Stearin angenommene Formel 
zu verändern. Er betrachtet es als Tristearin $=\mathrm{C}^{114} \mathrm{H}^{110 O} \mathrm{O}^{12}$ $=3 \mathrm{C}^{36} \mathrm{H}^{36} \mathrm{O}^{4}+\mathrm{C}^{6} \mathrm{H}^{8} \mathrm{O}^{6}-6 \mathrm{HO}$; in gleicher Weise Margarin und Palmitin als Trimargarin und Tripalmitin. Ausser den oben genannten Körpern hat Berthelot noch eine neue neutrale Verbindung der Chlorwasserstoffsäure mit dem Glycerin dargestellt, das Dichlorhydrin $\mathrm{C}^{6} \mathrm{H}^{6} \mathrm{Cl}^{2} \mathrm{O}^{2}=2 \mathrm{HCl}+\mathrm{C}^{6} \mathrm{H}^{8} \mathrm{O}^{6}-4 \mathrm{HO}$. Ein neutrales klares Oel, unlöslich in Wasser, von starkem ätherischen Geruch. Sein spec. Gew. ist 1,37. Durch Kali wird es langsam zersetzt in Glycerin und Chlorwasserstoffsäure.

Eine andere von Berthelot dargestellte neue Glycerinverbindung ist das Benzochlorhydrin $\mathrm{C}^{20} \mathrm{H}^{11} \mathrm{ClO}^{6}$ $=\mathrm{C}^{14} \mathrm{H}^{6} \mathrm{O}^{4}+\mathrm{HCl}+\mathrm{C}^{6} \mathrm{H}^{8} \mathrm{O}^{6}-4 \mathrm{HO}$. Sie dient als Beweis dafür, dass, wie es Verbindungen des Glycerins mit mehreren Aequivalenten ein und derselben Säure, ebenso auch solche giebt, die mehrere verschiedene Sïuren enthalten.

Erhitzt man Oxalsäure mit Glycerin bis $100^{\circ}$, so spaltet sie sich in reine Kohlensäure, welche entweicht, und in Ameisensiure, welche mit dem Glycerin verbunden blcibt, ohne jedoch eine neutrale Verbindung zu bilden. Bei überschüssigem Glycerin ist die Zersetzung nach 27 Stunden vollständig. Diese merkwürdige Zersetzung stimmt mit der häufig beobachteten Bildung der Ameisensüure auf Kosten der Oxalsäure.

$$
\mathrm{C}^{4} \mathrm{H}^{2} \mathrm{O}^{8}=\mathrm{C}^{2} \mathrm{O}^{4}+\mathrm{C}^{2} \mathrm{H}^{2} \mathrm{O}^{4} \text {. }
$$

Berthelot hat ferner eine der von Williamson entdeckten zusammengesetzten Aetherarten analoge Verbindung zwischen Glycerin und Alkohol dargestellt, das Diäthylin $\mathrm{C}^{14} \mathrm{H}^{16} \mathrm{O}^{6}=2 \mathrm{C}^{4} \mathrm{H}^{5} \mathrm{Br}+\mathrm{C}^{6} \mathrm{H}^{8} \mathrm{O}^{6}-2 \mathrm{HBr}$. Es wird erhalten, wenn man Glycerin, Bromäthyl und überschüssiges Kali 60 Stunden lang in verschlossenen Gefässen auf $100^{\circ}$ erhitzt. Die Flüssigkeit bildet alsdann zwei Schichten. Man giesst die obere ab und destillirt sie. Bei $191^{\circ}$ geht das Diäthylin über. Es ist ein klares, farbloses Oel, in Wasser wenig löslich, von schwach ätherischem Geruch. Sein spec. Gew. ist 0,92. Lässt man einige Tropfen auf glühenden Kalk fallen, so scheint sich Acrolein zu bilden. Mit einer Mischung von Schwefelsäure und Buttersäure destillirt, giebt das Diäthylin Butteräther. (Journ. de Pharm. et de Chim. Mai 1854.) 